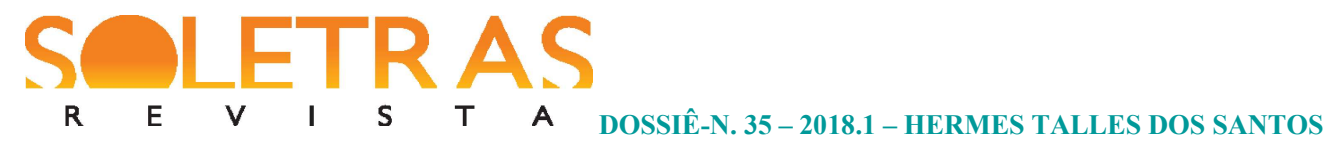

\title{
Ensino de língua portuguesa: entre a frase e o texto na sala de aula
}

\author{
Hermes Talles dos Santos ${ }^{1}$
}

\begin{abstract}
Resumo: No Brasil, o ensino de língua portuguesa e, especialmente, de gramática é foco de atenção de diferentes especialistas e teóricos, visando ao processo de ensino e aprendizagem da língua mais satisfatório e coerente com as orientações e teorias linguísticas científicas contemporâneas. Por isso, considerando e explicando a escolha do texto como base do ensino contemporâneo de língua materna, retomamos, brevemente, algumas questões relacionadas às concepções de linguagem, explanando como cada uma delas influencia no ensino da língua e da gramática. Na sequência, analisamos dois comentários postados em um ambiente virtual de aprendizagem de um curso a distância de formação continuada de docentes de língua portuguesa, visando a compreender os conhecimentos e as considerações apresentadas pelos professores. Verificamos que o mencionado curso oportunizou ampliação dos conhecimentos dos professores e demonstrou também que há a necessidade de maior aproximação entre os contextos acadêmico e escolar, para a construção de conhecimentos sobre o ensino de língua portuguesa e gramática coerentes com cenário educacional brasileiro.
\end{abstract}

Palavras-chave: Língua portuguesa. Gramática. Ensino e aprendizagem. Formação de professores.

\section{Introdução}

As orientações científicas contemporâneas para o ensino de língua portuguesa, presentes em documentos oficiais como os Parâmetros Curriculares Nacionais de Língua Portuguesa $^{2}$ (BRASIL, 1998), bem como constantes orientações da ciência linguística enfatizam o ensino da língua portuguesa pautado em textos. A eleição desse objeto de estudo não é fortuita: está alinhada ao desenvolvimento científico dos estudos sobre a aprendizagem da língua materna e de diferentes vertentes do paradigma construtivista de aprendizagem, além, também, de estar em consonância com currículos de diferentes países (cf. ROJO, 2008a).

Conquanto, do ponto de vista acadêmico e teórico, esse desenvolvimento científico tenha resultado em novas perspectivas acerca do ensino e aprendizagem da língua, deslocando a base do estudo linguístico da frase para o texto, com efeito, tal mudança não ocorreu na mesma proporção, no contexto escolar (cf. ROJO, 2008b). Apesar de o impacto das contribuições científicas poder ser notado em materiais didáticos, devido geralmente à escolha de textos autênticos - e não mais adaptados ou artificiais, isto é, construídos exclusivamente para o processo de ensino - pertencentes a gêneros discursivos/textuais outrora não usuais na Educação Básica (cf. ROJO, 2008a; 2008b), ainda hoje, no contexto escolar, parte do ensino

\footnotetext{
${ }^{1}$ Doutor em Estudos Linguísticos pela UFSCar. Professor e coordenador do curso de Linguagens da Faculdade SESI-SP Educação. SP, SP, Brasil. E-mail: hermao87@gmail.com.

${ }^{2}$ Doravante mencionado pela sigla PCN.
} 
de língua materna, principalmente a parcela relacionada ao ensino gramatical é pautado no estudo da frase, baseando-se em conceitos oriundos da Gramática Tradicional e Normativa, e mesclando-os com conhecimentos científicos mais contemporâneos.

Da mesma forma, o processo de ensino também mescla orientações tradicionais, baseadas em conceituação, aplicação e fixação de conceitos, com orientações mais contemporâneas, que partem do uso, promovem a reflexão e voltam-se, novamente, ao uso linguístico (cf. BRASIL, 1998). Assim, no contexto escolar, vertentes construtivistas são muitas vezes empregadas de forma hibridizada com noções ou estratégias de ensino ditas tradicionais. Não se trata de uma dicotomia excludente, em que ora ocorre uma, ora outra. $\mathrm{Na}$ prática cotidiana de ensino - a qual é global/holística, não discreta - essas perspectivas se entrelaçam, gerando nos docentes, responsáveis por garantir a aprendizagem discente, ações pedagógicas híbridas e coerentes, de acordo com seu ponto de vista, mas, de certo modo, do ponto de vista acadêmico, incongruentes.

Ocorre, no entanto, que essa hibridização é majoritária e constantemente malvista pela academia brasileira, a qual, de certa forma, parece considerar que a teoria científica é muitas vezes distorcida ou desconsiderada pelos professores propositalmente. Conforme SANTOS (2017), isso ocorre por conta da distância existente entre academia e escola no contexto brasileiro, o que contribui, do lado acadêmico, para a acentuação da visão de que os professores da Educação Básica não adotam as orientações científicas contemporâneas em sua prática pedagógica e, do lado escolar, de que os professores acadêmicos desenvolvem teorias não condizentes com a realidade dos ensinos fundamental e médio.

Visando a colaborar com professores, pesquisadores e especialistas no ensino de língua materna, partindo da premissa de que as viradas pragmática (FREGONEZI, 1999; BONINI, 2002, ROJO, 2008b), textual (ROJO, 2008a, 2008b, 2010) e discursiva (ROJO, 2008b, 2010) deslocaram, de algum modo, o ensino de língua portuguesa do estudo da frase para o texto, aprofundamos a discussão sobre as concepções de linguagem para demonstrarmos como elas influenciam o ensino linguístico, principalmente, no que concerne ao ensino gramatical. $\mathrm{Na}$ sequência, analisamos comentários realizados por dois professores de língua portuguesa em um ambiente virtual de aprendizagem, em um curso sobre o ensino de língua portuguesa e gramática, destacando como conhecimentos e noções de diferentes concepções de linguagem influem na prática docente. 


\section{As concepções de linguagem e o ensino de língua/gramática}

De modo geral, durante mais de dois milênios, o ensino linguístico foi orientado teórica e tecnicamente por pressupostos da concepção de linguagem conhecida como expressão do pensamento (GERALDI, 1984; NEDER, 1993; TRAVAGLIA, 2009). Essa concepção propiciou o desenvolvimento e o aprimoramento da Gramática Tradicional e, consequentemente, da Gramática Normativa. Nesse ponto, vale destacar que o objeto de estudo dessa gramática tem por limite máximo o nível da frase (ou da oração).

Historicamente, grosso modo, até meados do século $\mathrm{XX}$, o processo de ensino e aprendizagem foi baseado na abordagem e nos conhecimentos ditos tradicionais, que metodologicamente pautam-se na explicação conceitual do objeto de ensino pelo professor, para depois ocorrer a aplicação de tal conhecimento e sua fixação por parte do discente. Nesse sentido, os pressupostos teóricos das disciplinas do Trivium (Gramática, Retórica e Poética) envolviam o estudo de noções gramaticais tradicionais, bem como de textos literários clássicos e serviam adequadamente ao modelo de ensino tradicional. No que concerne ao estudo gramatical, a descrição da Gramática Tradicional foi amplamente utilizada por apresentar certa estabilização dos fatos linguísticos, descritos majoritariamente de forma discreta e categorizável, a partir da língua presente em textos literários clássicos que, geralmente, apresentavam uso da norma-padrão linguística e eram aceitos por parte da crítica literária. Nesse contexto, o caráter deôntico da Gramática Tradicional - bem como as prescrições da Gramática Normativa - se adequa satisfatoriamente ao modelo dito tradicional, porquanto nele o conhecimento está preponderantemente relacionado ao saber conceitos e regras.

Também é preciso considerar que o ensino, até pouco tempo, restringia-se a poucas pessoas. Apenas com a ampliação do processo educacional e com o desenvolvimento de pesquisas na área da aprendizagem, já na segunda metade do século XX, é que o processo de ensino e aprendizagem, como um todo, passou a ser repensado, pondo em questão a adequação do modelo tradicional à educação contemporânea (cf. BRASIL, 1998).

No Brasil, no que tange ao ensino linguístico, com a introdução das classes populares na escola, a partir da segunda metade do século XX, o modelo de ensino de língua materna dito tradicional mostrou-se inadequado e inconsistente, entre outros fatores, por trabalhar 


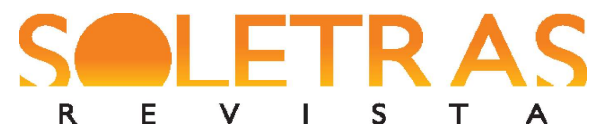

DOSSIÊ-N. 35 - 2018.1 - HERMES TALLES DOS SANTOS

exclusivamente com uma variante linguística que seria, para alguns, o modelo exemplar da língua portuguesa brasileira, mas que, em alguns casos, não condizia com a variante linguística empregada pelos estudantes em seu cotidiano. Nesse sentido, tal modelo mostravase inadequado quanto a consideração e reconhecimento dessas variantes linguísticas, até então não presentes no contexto educacional, pois, de certa forma, contribuía para a disseminação do preconceito linguístico (cf. APARÍCIO, 2001; SOARES, 2012) e para a aprendizagem de uma língua não condizente com a realidade de parte dos estudantes. O que se tinha, então, era uma distância muito grande entre a variante linguística - e os conceitos dela ou a ela relacionados - ensinada e a variante conhecida e dominada pelo estudante.

Nesse contexto, com a divulgação de pressupostos oriundos do paradigma construtivista de aprendizagem e do desenvolvimento da ciência linguística e dos pressupostos da concepção de linguagem como processo de interação (cf. NEDER, 1993) no contexto acadêmico brasileiro, o ensino de língua materna foi repensado de forma a, de um lado, condizer com a realidade sociocultural dos estudantes, para diminuir a distância entre aquilo que o estudante sabia e o que deveria aprender, e, de outro, adequar-se aos pressupostos científicos contemporâneos. Ocorre, então, a eleição do texto como foco do processo de ensino e aprendizagem. Com isso, o ensino deveria ocorrer não mais apenas em torno de enunciados isolados, mas a partir de textos. Essa mudança de enfoque acarretou para o ensino de língua materna nova forma de consideração das variantes da língua, uma vez que as variedades linguísticas padrão e não padrão são consideradas adequadas ou inadequadas, de acordo com questões discursivas próprias de cada gênero discursivo/textual ou das condições sociocomunicativas em que a interação verbal ocorre (BRASIL, 1998). Não se trata exclusivamente de ensinar uma ou outra variedade linguística, mas de ensinar o uso linguístico de forma contextualizada e relacionada à função, à situação e às características dos gêneros discursivos/textuais. Desse modo, no processo de ensino, o professor de língua materna, por meio de tal abordagem, consideraria a inadequação ou adequação de determinada variante linguística empregada por seu estudante, de acordo com a situação sociocomunicativa e o gênero discursivo/textual com que está trabalhando, sem prezar exclusivamente por uma ou outra variante, de forma dicotômica ou antagônica.

Usualmente, a eleição do texto como foco do processo de ensino e aprendizagem é conhecida por virada pragmática (BONINI, 2002), discursiva ou enunciativa (ROJO, 2010) no ensino de língua portuguesa. Como já dito, trata-se de uma mudança de paradigmas, 
deslocando "[...] o foco da frase para o texto e do enunciado para a enunciação" (FREGONEZI, 1999, p. 82). Para Bonini (2002, p. 26), essa virada

[...] corresponde à incorporação, no ensino, de uma série de perspectivas teóricas comprometidas com [o] funcionamento da linguagem para além de uma estrutura imanente voltada sobre si mesma, tais como: a teoria da enunciação, a teoria polifônica de Bakhtin, a AD (análise do discurso) anglosaxônica, o funcionalismo, a $\mathrm{AD}$ francesa, a análise da conversação e a linguística textual.

Com a incorporação de tais perspectivas teóricas, segundo Rojo (2010, p. 10), passou-se a enfocar, "[...] em sala de aula, o texto em seu funcionamento e em seu contexto de produção/leitura, evidenciando as significações geradas mais do que as propriedades formais que dão suporte a funcionamentos cognitivos”.

Rojo (2008b) demonstra que essa mudança ocorreu processualmente ao longo de certos períodos, o que a faz caracterizar basicamente três viradas no ensino de língua materna, que estariam inter-relacionadas. Contudo, como ela bem demarca: embora, no contexto escolar, o texto seja considerado como base ou objeto para estudo da língua, práticas gramaticais pautadas em noções tradicionais e normativas resistem e co(n)ocorrem no processo de ensino de língua portuguesa.

Segundo a autora (ROJO, 2008b, p. 11-12), na década de 70 do século XX, ocorreu a virada pragmática em que

[...] o texto ganha estatuto de principal unidade de ensino na sala de aula. Mas não ainda de objeto de ensino. O texto literário, publicitário, de entretenimento e jornalístico passa a ser utilizado em sala de aula para suportar procedimentos de leitura e de (re)produção, descritos e divulgados nas pesquisas de psicologia cognitiva e do processamento: as estratégias de leitura e modelos de processamento em produção. Temporariamente, a disciplina de LP perde "conteúdo" e se torna procedimental.

Na segunda metade da década de 80 , ocorreu a virada textual em que

o texto se torna objeto de ensino, não isento de uma gramaticalização escolar. [...] De certa maneira, por essa época, o "conteúdo" gramatical de LP se recompõe, dessa vez, incorporando nos eixos procedimentais de ensino, uma gramática pedagógica no nível do texto (as (super) estruturas da 


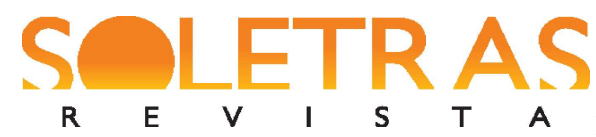

DOSSIÊ-N. 35 - 2018.1 - HERMES TALLES DOS SANTOS

narrativa e da dissertação/argumentação, sobretudo, mas também rudimento das noções de coesão e coerência) (ROJO, 2008b, p. 12).

Por fim, na última década do século XX, ocorreu a virada discursiva em que, por influência de conhecimentos oriundos de vertentes diferentes de análise do discurso, o texto é tomado

[...] como objeto fundamental do ensino de língua, a ponto de se discutir hoje a não necessidade do ensino de gramática por si só, mas ao mesmo tempo multiplicando as propostas de tratamento do texto na escola (como estrutura e forma; como acontecimento; como singularidade; como significação; como exemplar de gênero; como veículo de ideologias; como instrumento de constituição de identidades, alteridades e subjetividades; como instrumento de luta contra-hegemônica) (ROJO, 2008b, p. 12).

Como se percebe, em cada virada, a mudança processual de foco da frase para o texto não é tão simples; há bases conceituais bem profundas que precisam ser compreendidas para perceber os impactos produzidos no ensino e a aprendizagem da língua materna.

A consideração da frase como foco de ensino está, como já dito, relacionada, de modo mais explícito, à Gramática Tradicional que, por sua vez, foi edificada na concepção de linguagem conhecida como expressão do pensamento. Nessa concepção, a principal tese era de que a linguagem teria sua relação com a realidade sensível, isto é, externa ao sistema linguístico. Destarte, ela seria uma espécie de espelho ou reflexo da realidade. Essa realidade refletida seria apreendida pelo homem por meio de sua faculdade de pensar. Logo, para alguns, a linguagem era a expressão do pensamento construído pelo indivíduo em sua mente ou, para outros, era ela que possibilitava a faculdade de pensar, pois permitiria, por meio de constructos mentais, a ligação entre realidade sensível e pensamento. Em ambos os casos, o que temos é a linguagem como resultado de uma ação individual e não social, sempre vinculada ao indivíduo e a seu processamento mental.

Até mesmo quando se discute a natureza da língua enquanto instituição natural ou convencional, o ponto de partida não é, de fato, o uso social que dela se faz, mas como ela é processada psicológica ou mentalmente pelo indivíduo. Ora, pode-se advogar que toda comunicação é social, pois não haveria uma interação sem enunciador e coenunciador. Com isso, até mesmo essa tendência consideraria a língua como algo social, apesar de não se deter explicitamente dessa questão. Todavia, por mais que se queria ampliar a noção de social para 


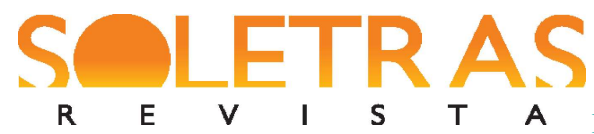

DOSSIÊ-N. 35 - 2018.1 - HERMES TALLES DOS SANTOS

essa tendência, ela é compreendida como união de indivíduos, em que cada um mantém sua individualidade, utilizando-se da língua enquanto produto pronto/acabado (cf. VOLOCHÍNOV/BAKHTIN, 2006). Temos, se possível, nessa perspectiva, um conceito de social muito restrito, em comparação a outras tendências.

Por isso, Neder (1993, p. 76) considera que "o exterior, isto é, as condições sociais constituem-se, para essa tendência, material passivo do que está no interior, no psiquismo do indivíduo". Ou seja, não se tem a ideia de grupo social ou de coletivo, nem se considera questões de ordem históricas e culturais. Mesmo acatando o uso convencional, mais próximo do conjunto de indivíduos, a linguagem é apreendida a partir dos indivíduos, do porquê socialmente empregam-na de dada forma, coerente ou não com alguns princípios que regulariam sua organização e realização. Nesse sentido, se há algum problema na produção de sentidos, esse problema está relacionado àquele que o produziu, pois sua exteriorização é considerada como errada, por apresentar falhas que estariam relacionadas a organização e estruturação.

De forma direta, o problema manifestado na língua estaria, na verdade, na construção do pensamento da qual ela seria a expressão. Com isso, como destaca Travaglia (2009:21), “as pessoas não se expressam bem porque não pensam”. Como nos adverte Neder (1993:77) “[...] o pensamento deve ser organizado, portanto, obedecendo a uma determinada lógica. Isso significa que, se o indivíduo, não se utilizar dessa lógica, dificilmente terá condições de organizar seu pensamento".

É preciso demarcar que o nível mínimo de análise dessa tendência concerne às letras (que, por vezes, se confunde com o som que representam graficamente) e o máximo, à frase (ou oração). É neste nível que se discute a construção linguística de forma coerente com questões, de um lado, lógica e, de outro, culturais, por meio das prescrições normativas. A noção de que haveria uma lógica para a correta expressão do pensamento, aliada a questões históricas e políticas, proporcionou o desenvolvimento de preceitos para a normalização da língua. Com isso, por deriva, aqueles que não empregassem tais normas em suas expressões verbais, comunicar-se-iam por meio de um modelo deturpado, de pessoas não cultas, e, assim, de modo direto, revelariam que não sabiam pensar satisfatoriamente.

As regras da correta expressão verbal foram construídas a partir de modelos idealizados de uso linguístico, encontrados em autores literários que representariam a língua ideal de determinado grupo social. Podemos ponderar que há nisto um fator de natureza 


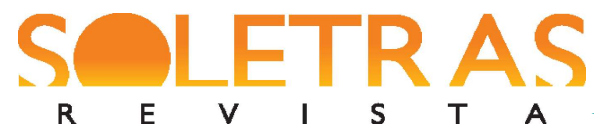

DOSSIÊ-N. 35 - 2018.1 - HERMES TALLES DOS SANTOS

cultural para regular o emprego linguístico. Historicamente, o apreço pela cultura clássica, quando essa estava em risco de desaparecer ou de se perder, devido a fatores diversos, conduziu os gregos do período helenístico, que queriam mantê-la intacta, a vislumbrar na língua um ponto de união social e manutenção de determinada cultura tida como de prestígio (NEVES, 2005). Dessa forma, para resgatar a linguagem de outrora, era preciso livrar a língua daquilo que se considerava como imperfeição ou deturpação. Nesse ponto, o que se objetivava, na verdade, era impedir o curso natural de desenvolvimento e atualização das línguas, por meio de normas que obrigassem os indivíduos a retomar a língua arcaica, idealizada e livre de degenerações. É preciso ressalvar que a noção de desenvolvimento e atualização das línguas é relativamente recente na história dos estudos linguísticos. Assim, não haveria como requerer que a concepção de linguagem como expressão do pensamento considerasse em suas proposições tais aspectos.

Baseando-se na premissa de que as normas para o emprego da língua corresponderiam à construção lógica do pensamento e, por conseguinte, a uma boa expressão, com o passar do tempo, tal normatividade serviu, a nosso ver, a propósitos políticos. Com a ideia, mesmo que implícita, de que a língua permitiria certa união social, era preciso criar regras para dada variante linguística, escolhida, por fatores políticos, como a representante de determinado grupo sociopolítico. Ou seja, era preciso que houvesse uma padronização do uso de determinada língua, por meio da eleição de uma variante como a representante modelar do bom uso linguístico (GNERRE, 2009; WEEDWOOD, 2002).

Essa normatização linguística, por estabelecer padrões para o uso da língua, recorrendo a textos literários - tidos como representantes de uso da língua exemplar -, resultou naquilo que Lyons (1979) aponta como um dos erros clássicos da tendência de concepção da linguagem enquanto expressão do pensamento: a submissão da modalidade linguística oral à escrita. Com isso, gerou-se a crença nas pessoas de que as regras da escrita também seriam aplicáveis à fala e que quanto mais a fala de alguém se aproximasse dos modelos da escrita, mais sua expressão linguística seria livre de imperfeições, demonstrando que o indivíduo possuía um pensamento bem articulado. Assim, cada vez mais, associou-se que a variante oral culta de determinada língua, mais próxima da norma-padrão da escrita, corresponderia à verdadeira língua e, por questões sociais, históricas e culturais, os sujeitos de determinada sociedade que a empregassem seriam modelos a serem seguidos, pois representariam o bem falar, além de serem considerados cultos. 
Desenvolvida sobre tais pressupostos, nessa concepção, a gramática é considerada como um conjunto de preceitos a ser apreendido pelo sujeito para conseguir falar e escrever corretamente, segundo a norma-padrão da língua (cf. NEDER, 1993); ou como define Travaglia (2009, p. 24, grifo do autor), "gramática é concebida como um manual com regras de bom uso da língua a serem seguidas por aqueles que querem se expressar adequadamente". Portanto, gramática para tal orientação é um conjunto de regras e normas arbitrárias, baseadas, muitas vezes, em fatores externos à própria língua, isto é, pautadas em questões não puramente linguísticas, mas lógicas, filosóficas, estilísticas ou culturais que regulam e prescrevem aquilo que seria o uso correto da língua. Destacamos que gramática, aqui, está intimamente relacionada à apreciação valorativa de uso linguístico tido como correto ou incorreto. Podemos dizer que estamos tratando da Gramática Normativa, que encontra na Gramática Tradicional base para sustentar suas prescrições em relação ao uso linguístico.

Em contrapartida à concepção de língua conhecida como expressão, foi desenvolvida, durante a primeira metade do século $\mathrm{XX}$, a tendência linguística conhecida como instrumento de comunicação (cf. GERALDI, 1984; NEDER, 1993, TRAVAGLIA, 2009), que compreende basilarmente a língua enquanto um sistema linguístico, o qual é considerado um fato objetivo, externo ao indivíduo e constituído por conjunto de elementos linguísticos idênticos. Essa tendência, concomitantemente, compreende que o sistema linguístico garante o entendimento dos falantes de uma mesma língua, mas está basilarmente relacionado ao indivíduo, quando interage verbalmente.

A comunicação seria um ato social - no sentido estrito do termo - que necessitaria de, no mínimo, dois indivíduos para ocorrer. Além disso, na situação comunicativa, seria preciso que os indivíduos compartilhassem a utilização e o funcionamento do código constituinte da língua. Caso algum dos envolvidos não tenha tal domínio, sua produção ou compreensão dos enunciados seria falha, o que dificultaria o estabelecimento efetivo da comunicação. Assim, assevera Neder (1993) que, para essa tendência, há regras inerentes ao sistema linguístico e constituintes da língua que devem ser seguidas pelos falantes para que haja estabelecimento efetivo da comunicação.

Devemos destacar que, nessa concepção de linguagem, já há de certo modo o deslocamento do interesse exclusivo da frase para o texto - contudo, aqui, texto não possui o entendimento da concepção enquanto processo de interação. Nesta concepção, texto parecer ser compreendido enquanto a união de elementos linguísticos para o estabelecimento da 


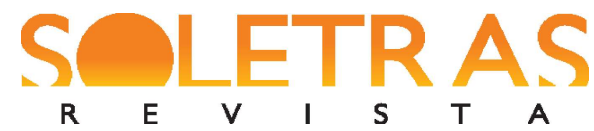

DOSSIÊ-N. 35 - 2018.1 - HERMES TALLES DOS SANTOS

comunicação. Assim, tal noção fica muito atrelada ao domínio intralinguístico, não dando tanto peso a fatores contextuais. Além disso, ocorre que, devido ao interesse em descrever o funcionamento linguístico, a atenção dessa concepção linguística ficou restrita a porções delimitadas da língua e não ao todo: partes do texto, como palavras, sentenças, orações ou períodos eram analisados discretamente, recorrendo à fatores culturais, históricos ou sociais, apenas quando era preciso justificar alguma ocorrência acidental de algum elemento linguístico.

Como a segunda tendência considera que o sistema linguístico seja relativamente estável, imutável e definitivo, e, dessa forma, não se submeteria às subjetividades individuais, nela a gramática é tida como algo estabelecido pela própria estrutura linguística, a partir de regularidades em construções linguísticas. Como a língua é entendida, em certo sentido, como algo pronto ou acabado, os indivíduos devem se submeter as suas regularidades, isto é, à gramática da língua, a fim de construir enunciados comunicativamente inteligíveis. Segundo essa perspectiva, a gramática de uma língua pode ser deduzida a partir da análise de um conjunto de enunciados, os quais relevam o funcionamento da língua, por meio da organização e estruturação de seus elementos. A nosso ver, nesta tendência, gramática está intimamente relacionada à estrutura da língua, pois, a partir dela, se enxertariam e combinariam discretamente elementos para a construção de enunciados. Como em um quebra-cabeça tais elementos teriam lugar previsto para seu encaixe. Nesta tendência, a especificação da gramática é dada pelo termo descritiva, pois sua compreensão resulta de um processo de descrição da estrutura linguística, para a compreensão de seu funcionamento.

Geralmente, o processo de ensino e aprendizagem de língua materna pautado na concepção da linguagem como instrumento de comunicação propõem o desenvolvimento de atividades centradas no código ou em seu uso. O intuito é demonstrar ao aprendiz como a língua é empregada em dadas situações comunicativas. Nesse caso, alguns exemplos mais regulares de sentenças são utilizados para exemplificar o uso linguístico e servem, também, como modelos de sentenças para a aprendizagem. Segundo Travaglia (2009, p. 28),

a consideração dessa linguística da fala, desses estudos sobre a língua em uso, é importante para o trabalho do professor de língua materna que pretende (de acordo com objetivo que se proponha) desenvolver a competência comunicativa de seu aluno ou descrever-lhe como é e como funciona a língua que ele utiliza ou levá-lo a observar esses mesmos fatos (a constituição e funcionamento da língua). 
Partindo de exemplos reais de uso da língua, escritos ou orais, os aprendizes devem depreender como a ela funciona, por meio da análise discreta de seus elementos constituintes. Segundo Neder (1993), valendo-se de exercícios estruturais, o ensino da língua procura conduzir o estudante à aprendizagem dos elementos dentro sistema linguístico, como intuito de que o aluno internalize regras linguísticas diferentes daquelas que possui. De acordo com a autora (NEDER, 1993, p. 87),

\begin{abstract}
O objetivo é que o adquira hábitos linguísticos que são reações aprendidas e que se repetem em circunstâncias semelhantes. Esse tipo de ensino enfoca, sobretudo, o saber fazer. Através da repetição, o aluno irá absorvendo as formas que comporão seu universo linguístico, ficando munido de estruturas que o auxiliem no aperfeiçoamento da capacidade de uso de um meio de comunicação.
\end{abstract}

Trata-se, portanto, de exercícios, de certa forma, mecânicos, que visam o domínio da estrutura linguística que possibilita a realização de diferentes registros linguísticos. O importante é compreender o funcionamento da língua em dada comunidade e situação, inserindo, como pontua Neder (1993, p. 83), “[...] progressivamente a noção de nível [ou registro] de língua: familiar, formal etc.”, para explicar variações ocorridas na superfície da estrutura linguística.

Embora não haja, a priori, a apreciação linguística de que uma variante linguística seja melhor que outra, como ocorre na primeira tendência, escamoteadamente pode-se conduzir o estudante a se apropriar de estruturas que correspondam, por exemplo, somente a dada variante de prestígio social, se se escolher exemplos somente dessa variante. Assim, os exercícios podem indiretamente corrigir as estruturas que os estudantes possuem previamente.

Nesta tendência, o fito do processo de ensino e aprendizagem de língua materna é desenvolver a competência comunicativa do estudante, isto é, sua capacidade de construção e compreensão dos enunciados linguísticos em situações comunicativas. Podemos notar que a preocupação não recai apenas sobre a compreensão da dimensão formal da língua, mas também sobre sua dimensão funcional. A não compreensão de um enunciado pode estar associada: ao não domínio do código ou do sistema linguístico; à falha no emprego linguístico da dimensão formal ou funcional. Ou seja, tais problemas estão relacionados à competência comunicativa do falante. 


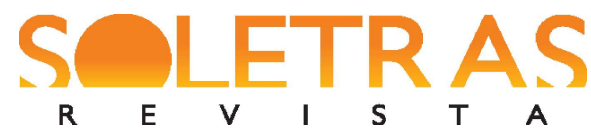

Apesar de romper com a tradição gramatical, propondo um processo de ensino e aprendizagem científico e não especulativo, em que a língua é considerada como constituída por duas modalidades, oral e escrita, com regras próprias, independentes da realidade sensível e, de certo modo, como algo social e não apenas individual, a compreensão da linguagem como instrumento de comunicação parece considerar a língua como um artefato, do qual se pode e deve ter o maior conhecimento possível para entender seu funcionamento e, consequentemente, garantir um uso efetivamente satisfatório. A nosso ver, no plano educacional, isso pode gerar a noção de que, antes de usar a língua, é preciso conhecê-la, conduzindo a seu não emprego efetivo em situações comunicativas, mas a exercícios de estudo e descrição, com base na crença de que a compreensão do sistema linguístico e seu funcionamento garantiria o emprego linguístico de modo satisfatório.

Por sua vez, a consideração do texto como foco de ensino, de forma mais delimitada, está associada a concepção linguística conhecida porprocesso de interação (GERALDI, 1984; NEDER, 1993; TRAVAGLIA, 2009). É preciso pontuar, conforme o faz Rojo (2008a, 2008b) que, antes do desenvolvimento científico dessa concepção, o ensino de língua baseado no Trivium, por meio das disciplinas curriculares de Retórica e Poética, a sua maneira, pautavase em textos, utilizando-se de uma abordagem tradicional, em que "[...] os textos valorizados da tradição clássica entravam nas aulas como base de exercícios pedagógicos para o bem-falar e o bem-escrever, como unidade de ensino e função modelar, embora secundários face ao ensino de gramática" (ROJO, 2008b, p. 9).

A concepção de linguagem conhecida como processo de interação foi desenvolvida no século XX como contraproposta a pressupostos, em parte, da tradição gramatical e, em parte, da perspectiva linguística estruturalista, principalmente, a de origem europeia. Nessa concepção, a linguagem é considerada como um fenômeno genuinamente social e dialógico. Conforme destaca Geraldi (1984, p. 43), na concepção de linguagem enquanto processo de interação ${ }^{3}$, “[...] a língua só tem existência no jogo que se joga na sociedade, na interlocução, e é no interior de seu funcionamento que se pode procurar estabelecer as regras de tal jogo".

No que concerne à ideia de interação, Antunes (2014, p. 18, grifos da autora) pontua que

\footnotetext{
${ }^{3}$ Demarcamos que Geraldi (1984) refere-se a tal concepção de linguagem como forma de interação, não como processo, como adotamos aqui. Essa maneira de referir-se a tal concepção é empregada por Neder (1993).
} 
O conceito de "interação", como está sinalizado pela própria composição da palavra, aplica-se a toda "ação" "entre" dois ou mais sujeitos. Representa uma ação conjunta; uma atividade realizada por mais de um agente. No caso específico da linguagem verbal - que é o que nos interessa aqui - a interação, além de ser uma ação conjunta, é uma ação recíproca, no sentido de que os participantes exercem, entre si, mútuas influências, atuam uns sobre os outros na troca comunicativa que empreendem.

Nesse sentido, temos a noção - muito importante para esta concepção - de que "toda ação de linguagem é dialógica" (ANTUNES, 2014, p. 19), pois o jogo linguístico e o empreendimento de jogá-lo do sujeito (cf. GERALDI, 1984) envolvem, minimamente, uma ação conjunta e recíproca de troca de saberes, de informações, de propósitos, e de estabelecimento de parceria e dos contratos sociais, histórica e culturalmente estabelecidos. Ademais, os envolvidos podem aceitar ou não participar de tal jogo. O aceite positivo ou negativo para a instauração da interação linguística só ocorre por conta do fato de que a linguagem é constitutivamente responsiva - outra noção cara a essa concepção. Destarte, o que temos sempre em uma atividade linguística não é apenas uma troca de informações, mas uma ação conjunta e recíproca entre os sujeitos envolvidos, no sentido de estabelecer/manter ou não essa atividade.

Podemos compreender que a interação verbal visa a sempre compreender os sentidos linguísticos, construídos colaborativamente entre/pelos sujeitos durante a atividade linguística, com base, sempre, em fatores ideológicos e impregnados por questões sociais, históricas e culturais. Destarte, a linguagem seria um fenômeno social, pois ganharia forma no processo tensivo de interação verbal, em que concorrem para sua modelagem elementos linguísticos e fatores sociológicos, culturais e históricos. Logo, não há, de antemão, regras descontextualizadas que sejam capazes de prever ou orientar a organização da língua, mas, de acordo com as finalidades e objetivos pretendidos na instauração da atividade comunicativa, os participantes da interação verbal mobilizam conhecimentos mediatos e imediatos que modelam tensivamente os enunciados linguísticos nela utilizados.

Logo, não existiriam sentidos literais e figurados, ou predeterminados, uma vez que o sentido é construído na interação verbal. Isso reforça a consideração de que não se pode trabalhar a língua destacando preliminarmente seus domínios e elementos, ou criando-lhes contornos (con)textuais. Contexto e língua estão completamente relacionados e imbricados. Fatores contextuais e linguísticos não se revestem um do outro, mas se fundem, na interação verbal, para a produção de sentidos. Por isso, conforme pondera Neder (1993, p. 80), “a 
comunicação verbal só pode ser explicada e compreendida nas relações de interação concreta e na situação extralinguística, não só a situação imediata, mas também, através dela, o contexto social mais amplo". Dessa maneira, também fatores da realidade sensível são considerados nesta abordagem, porém, não como na concepção tradicional, em que eles regeriam a constituição interna da linguagem, mas, de maneira tensiva, influenciando os indivíduos na formatação e adequação de seus enunciados de acordo com a situação comunicativa.

Nesse sentido, como a linguagem depende de seu contexto, não há espaço para considerar que haja determinada forma linguística ou variante melhor ou pior que outra. Nesse imbricado processo comunicativo, o que se tem é a possibilidade de inadequação ou adequação de determinada variante em dada situação comunicativa, segundo as regras sociais de dada comunidade discursiva (SWALES, 1990). Isso não implica que uma variante linguística possa receber maior ou menor prestígio da sociedade em que ocorre, porém é preciso demarcar que isso não é provocado por essa concepção de linguagem, é por ela previsto, uma vez que se considera o social como constituído por fatores ideológicos e políticos que incidem sobre todas as atividades humanas.

É nessa tensão, durante a ação discursiva em uma atividade de interação verbal que a gramática da língua é constituída. Pontua Antunes (2014:39, grifos da autora), “[...] a gramática, enquanto elemento constitutivo das línguas, é sempre contextualizada, uma vez que nada do que dizemos - oralmente ou por escrito - acontece em abstrato, fora de uma situação concreta interação". Nesse sentido, a língua só pode ser compreendida e analisada em ações comunicativas situadas sócio-historicamente. Por isso, para essa concepção de linguagem, o texto verbal, oral ou escrito, é o meio capaz de situar satisfatoriamente a interação comunicativa. Texto, aqui, é resultado da urdidura de elementos intralinguísticos (fonológicos, morfológicos, lexicais, sintáticos, semânticos e pragmáticos) entrelaçados a fatores extralinguísticos (ideológicos, sociológicos, históricos e culturais).

A nosso ver, nessa concepção seria adequado pensar em gramática como um conjunto de relações estabelecidas entre elementos linguísticos e fatores contextuais, imediatos e mediatos, que dão aos enunciados linguísticos formas adequadas e distintas conforme as situações comunicativas em que ocorrem. Em outras palavras, a gramática é elemento não apenas da atividade linguística, mas também discursiva (cf. ANTUNES, 2014). Como pontua Neder (1993, p. 88), nessa concepção, “as gramáticas da língua são entendidas, 


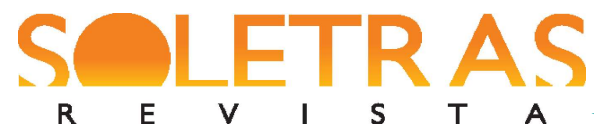

portanto, como conhecimento produzido coletivamente a partir de um trabalho produzido coletivamente nas situações concretas de interação verbal, um conhecimento de língua construído pelo seu uso efetivo".

No que tange ao ensino, a concepção da linguagem como processo de interação, como pontua Neder (1993, p. 88), proporciona ao estudante “[...] a oportunidade de aprender diferentes variedades da língua, adequadas a diferentes situações. $\mathrm{O}$ ensino tem por objetivo colocar o aluno, portanto, em situações efetivas de uso da língua". Esse contato é promovido por meio do ensino de língua através de diferentes textos, pertencentes a distintos gêneros do discurso/textuais, que, como já vimos, carregam concretizados em sua constituição traços contextuais imediatos e mediatos.

Em suma, temos basicamente, na tendência linguística enquanto expressão do pensamento, a compreensão da língua enquanto ato individual, resultante de processos ou relações estabelecidas no nível do pensamento, a partir da organização extralinguística, própria da realidade ou do mundo sensível. Sua noção de gramática, por um lado,está intimamente relacionada a prescrições arbitrárias que pretendem normalizar o uso linguístico, principalmente da escrita, mas que se estendem, por contiguidade, à fala; por outro, devido a questões lógicas e filosóficas, descrição e categorização das partes que constituem a língua, limitando-se à frase ou à oração como nível máximo de análise e descrição. Mesmo sua noção de período situa-se basicamente na junção de orações.

Na segunda tendência, instrumento de comunicação, temos a compreensão da língua como ato social, em um sentido estrito, pois toda a mobilização comunicativa se voltada basicamente para o indivíduo, que é o grande responsável por mobilizar o código da língua disponibilizado pelo sistema linguístico. Tal sistema, inerente à constituição da língua, é externo ao indivíduo. Nessa concepção, gramática é entendida como conjunto de regras dominadas pelos falantes e que são empregadas na construção de sentenças linguísticas inteligíveis. É preciso pontuar que regra não equivale à norma, pois a primeira advém da regularidade das construções linguísticas, enquanto a segunda é uma prescrição, oriunda de idealizações acerca do uso modelar da língua. Por isso, na segunda concepção, temos a noção de gramática descritiva, justamente por descrever as regularidades ou não da língua. Apesar de já romper, em certo sentido, o limite da frase, essa tendência linguística não foca seus estudos no texto, ficando mais limitada à estrutura e ao uso linguístico que permitiriam compreender o sistema linguístico que opera e possibilita a realização da língua. 


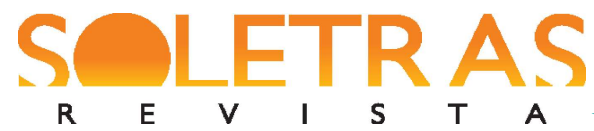

DOSSIÊ-N. 35 - 2018.1 - HERMES TALLES DOS SANTOS

Por sua vez, na tendência como processo de interação, temos a compreensão da linguagem como ato social de interação, intimamente relacionada e modelada por questões culturais, históricas e ideológicas. Sua noção gramática envolve a compreensão das relações que articulam e, ao mesmo tempo, tornam possível a construção de enunciados linguísticos ou de textos. A gramática para tal concepção linguística é construída durante a situação de interação verbal, por isso, Neder (1993) define-a como produtiva, pois é responsável, na interação, por organizar os enunciados linguísticos ou textos, conforme fatores linguísticos e contextuais, para promover a dialogicidade entre os falantes. Desse modo, o foco dessa tendência não está na frase, nem no código ou na estrutura linguística, mas no texto, que está intimamente relacionado à situação comunicativa, e da qual depende para a construção de seus enunciados e, por conseguinte, para a produção de sentidos.

\section{Ensino de língua portuguesa: gramática e texto, na prática}

A eleição do texto como objeto de ensino é, como explanado anteriormente, resultado de uma mudança de concepção de linguagem e, concomitantemente, de abordagem de ensino. Consideramos que essa mudança seja ainda recente, do ponto de vista histórico. Nesse sentido, na atualidade, certamente temos no contexto escolar de Educação Básica muitos professores que tiveram sua formação inicial sob molde de conhecimentos linguísticos tradicionais ou científico, mas preponderantemente consoante às vertentes estruturalistas. Além disso, a experiência de muitos professores enquanto discente remete à abordagem tradicional, ao ensino gramatical tradicional e à tomada do texto como procedimento de leitura ou de (re)produção textual (cf. ROJO, 2008b). Nesse sentido, para grande parte dos professores, a tomada do texto enquanto objeto de ensino é muito mais teórica do que algo prático, pois, de certo modo, seus saberes docentes (cf. TARDIF, 2013) ainda se pautam em conteúdos e práticas ditas tradicionais.

A influência dos conhecimentos baseados na concepção de linguagem como expressão do pensamento é forte em nossa sociedade e, principalmente no meio escolar. Heinig \& Buttchevitz (2009) demonstram que, apesar de estudantes em fase de conclusão da graduação em Letras possuírem conhecimentos da concepção de linguagem enquanto processo de interação, parte deles ainda relata em seus relatórios de estágios supervisionados a realização, por eles próprios, de práticas que consideram a língua e a gramática a partir da concepção de linguagem enquanto expressão do pensamento. 


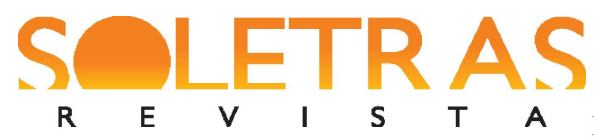

Também Santos (2017) percebe que há certa distância entre a concepção de linguagem declarada pelos professores e suas propostas práticas de trabalho gramatical. Muitas das justificativas apresentadas pelos docentes para a manutenção ou a necessidade do ensino gramatical pautado em moldes e conhecimentos tradicionais se dá,em parte, por conta de certa cobrança social, dos pais dos estudantes e de processos seletivos, e também de materiais didáticos adotados nas escolas, apesar de tais materiais didáticos trazerem muitos textos autênticos, de diferentes gêneros discursivos/textuais. Considerando que as orientações e documentos oficiais elegem o texto como foco de ensino e tal proposta chega, de alguma forma, à escola e impacta a prática docente, isso faz com que os professores da Educação Básica se sintam pressionados em dar conta, de um lado, das orientações científicas e oficiais contemporâneas e, de outro, das demandas sociais, o que os faz adotar práticas híbridas, trabalhando, por um viés, o texto e, por outro, tentando relacionar de forma satisfatória a ele, a gramática de cunho tradicional e normativa.

Do ponto de vista acadêmico, é compreensível que, com as viradas supracitadas no processo de ensino de língua materna, o foco ou a ênfase a atividades de categorização ou aplicação de preceitos gramaticais normativos tenha sido desmotivado ou desencorajado. Ao tomar o texto como unidade básica ou objeto de estudo, questões relativas a organização, estruturação e construção de sentidos, bem como aspectos referentes a circulação, produção e consumo dos textos sejam mais pertinentes para a construção de leitores, falantes, ouvintes e escritores competentes. No entanto, do ponto de vista escolar, por questões e pressões institucionais e sociais (cf. SANTOS, 2017), o ensino de língua portuguesa manteve e hibridizou esses conhecimentos científicos a noções gramaticais através de conceitos, categorizações e prescrições da Gramática Tradicional e Normativa.

Nossa experiência profissional enquanto formador de professores de língua portuguesa, seja em cursos presenciais ou virtuais, demonstra que os docentes necessitam de cursos de formação continuada voltados ao ensino linguístico pautado em textos e ao desenvolvimento de atividades gramaticais em uma perspectiva interacionista. Ao mesmo tempo, também revela que a academia precisa se aproximar cada vez mais das escolas para poder contribuir com propostas significativas que colaborem tanto com o desenvolvimento dos professores da Educação Básica, como com o desenvolvimento científico acadêmico.

A última edição do curso Gramática e Ensino de Língua Portuguesa, ofertado por meio do Portal dos Professores da UFSCar, através da plataforma MOODLE, no segundo 
semestre de 2017, teve cerca de 330 inscritos, para 60 vagas disponíveis. Nesse curso, observou-se que os professores estão preocupados com sua formação continuada, mas, por questões institucionais ou pessoais, visto que muitos trabalham com carga horária completa e são pais ou mães com afazeres domésticos, ou por questões de acesso ou ofertas a cursos, já que o Brasil possui regiões geográficas remotas ou isoladas, muitos deles tendem a desenvolver seus conhecimentos profissionais (cf. TARDIF, 2015) por meio de leituras teóricas particulares ou promovidas pelos gestores escolares, e abordagens empregadas em materiais didáticos (BRITTO, 1997; KLEIMAN \& MARTINS, 2007). Com isso, muitas vezes, há certa hibridização dos conhecimentos teóricos para sua aplicação prática. Trata-se, a nosso ver, do fenômeno das representações sociais (MOSCOVICI, 2015) que procura, através de um mecanismo particular, em um processo de recorte e estabilização de conhecimentos até então desconhecidos, como os científicos contemporâneos, articulá-los à conhecimentos já possuídos, de forma a transformar o novo conhecimento em algo familiar, para que seja passível de aplicação prática.

Consideremos dois comentários extraídos do módulo final do curso anteriormente mencionado e escolhidos por demarcarem que o ensino deva pautar-se em textos. Antes, faznos necessário, pontuar que todo o curso visou a discutir o ensino gramatical não de modo meramente prescritivo, mas produtivo para a formação de um estudante como usuário competente da língua portuguesa. Para isso, discutiu-se, entre outras coisas: as concepções de linguagem com base em Neder (1993), o ensino gramatical por meio de Franchi (2006a; 2006b) e as atividades gramaticais produzidas pelos participantes durante o curso.

Tamires $^{4}$

O ensino da Língua Portuguesa apresenta-se vinculado a concepções de linguagem e conceitos de gramática. É preciso discernir o que se objetiva ensinar e a partir disso ter em mente uma concepção de língua e um conceito de gramática apropriado a esse objetivo Há diferentes formas de se conceber a linguagem: como expressão do pensamento (ligada aos estudos tradicionais, o indivíduo que não sabe se expressar, não pensa ), como meio objetivo de comunicação (a língua é vista como um código, capaz de transmitir uma mensagem, informações de um emissor a um receptor) e como processo de interação verbal (baseada nas teorias de Bakhtin, defende que o lócus da linguagem é a interação). A gramática tem como principal função regular a linguagem e estabelecer padrões de escrita e fala para os falantes de uma língua, sendo dividida em tipos distintos: internalizada, normativa, descritiva, comparativa. O ensino da gramática por si só não tem nenhum valor, é necessário levar o aluno a perceber o verdadeiro sentido que determinado elemento exerce em uma frase e as inúmeras possibilidades que o mesmo possa exercer em um texto, já que a gramática existe em função do que as pessoas escrevem nas práticas sociais da língua. Atingir a competência comunicativa, não quer dizer que necessariamente é preciso incorporar um conjunto de itens lexicais

\footnotetext{
${ }^{4}$ Os nomes dos participantes foram alterados para que suas identidades fossem preservadas. Além disso, concordaram com a análise de seus comentários, por meio de autorizações escritas. 


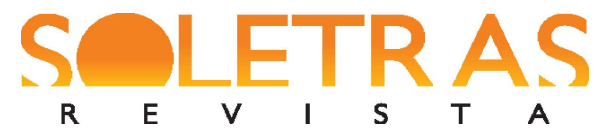

DOSSIÊ-N. 35 - 2018.1 - HERMES TALLES DOS SANTOS

ou conjunto de regras, mas sim verificar que regras devem ser usadas na construção de certos enunciados, como textos orais ou escritos. É necessário levar em conta os interlocutores e os objetivos/finalidades do processo de comunicação.

Tamires inicialmente pontua que o processo de ensino está relacionado às concepções de linguagem e aos conceitos de gramática. Contudo, dependendo do objetivo de ensino, o professor assumiria uma concepção linguística e gramatical. Com isso, podemos deduzir que diferentemente do que propõem documentos oficiais, como os PCN (BRASIL, 1998), segundo a docente, os professores se utilizariam de diferentes noções, a depender se seus objetivos de ensino, que podem estar relacionadas a diferentes tendências linguísticas e não exclusivamente a uma única concepção linguística.

Após explicar satisfatoriamente cada uma das concepções linguísticas, Tamires define o que entende por gramática - anteriormente ela pondera que há diferentes conceitos sobre o que seja gramática, mas, depois, apresenta apenas um: gramática regula a linguagem e estabelece padrões linguísticos para a escrita e para a fala. Como vimos, a primeira parte de sua definição poderia ser associada à concepção de língua como instrumento de comunicação, pois nela a gramática é entendida como regulagem da estrutura linguística. Todavia, considerando que o termo regular pode ser também entendido como sinônimo ajustar e pela segunda parte da definição apresentada, parece-nos que tal definição mescla elementos ou ancora-se basilarmente na concepção de linguagem enquanto expressão do pensamento, em que haveria um padrão idealizado de uso linguístico, justamente normalizado pela Gramática Normativa.

A fim de explicitar o que seja gramática, a mencionada professora cita quatro tipos: internalizada, descritiva, normativa e, por fim, comparativa. $\mathrm{O}$ último tipo citado não apareceu em nenhum dos textos indicados para estudo durante o mencionado curso. Possivelmente Tamires tenha conhecimento dessa vertente de estudos gramaticais, porém, do ponto de vista acadêmico, essa vertente abarca uma série de conhecimentos científicos que não se resumem exclusivamente a um tipo de gramática, mas a uma linha de estudos linguísticos, tornando estranha sua aproximação direta aos demais tipos anteriormente citados.

Depois, Tamires pondera que o ensino de gramática por si só não tem muita eficácia na aprendizagem discente, pois ele não possibilita a percepção da função dos elementos linguísticos em frases e das diferentes possibilidades de tais elementos em textos, para a produção de sentidos. Como, anteriormente, ela define gramática de um modo muito próximo 
à concepção de linguagem enquanto expressão do pensamento, inferimos que ela esteja se referindo a tal noção gramatical. Vale destacarmos que, a nosso ver, a crítica feita pela docente dirige-se a uma gramática estática, pronta, que não permite a compreensão de que os elementos linguísticos assumem diferentes usos em enunciados para a construção de sentidos, por isso, ela demarca que a gramática, enquanto um elemento da língua, só existe em função das práticas sociais de escrita. A noção de gramática apresentado por Tamires transita: parte da noção linguística enquanto instrumento de comunicação; baseia-se majoritariamente na noção mais corriqueira, próxima à concepção linguística conhecida por expressão do pensamento; aproxima-se da concepção de linguagem como processo de interação; mas retorna à primeira concepção (expressão do pensamento), por considerar que a gramática concerne a produções textuais escritas, parecendo, assim, acreditar que textos orais não possuiriam gramática.

Por fim, Tamires conclui seu comentário considerando que para o atingimento da competência comunicativa - considerando competência como um nível a ser alcançado e não como uma faculdade do falante de determinada língua, ou seja, uma visão um pouco diferente daquela proposta pela segunda tendência linguística, instrumento de comunicação - não satisfaria a incorporação de itens ou conjuntos de regras, em uma perspectiva mecânica, segundo a segunda tendência de linguagem. Para ela, a competência comunicativa seria alcançada por meio da reflexão sobre quais regras usar na construção de enunciados orais ou escritos, considerando os interlocutores e os objetivos da interação verbal. Nesse ponto, temos claramente uma hibridização de conceitos oriundos basicamente de duas concepções linguísticas distintas: instrumento de comunicação e processo de interação.

O comentário de Tamires evidencia-nos como conhecimentos teóricos são reinterpretados pelo indivíduo para que lhe seja compreensível. Tal como propõem o fenômeno das representações sociais de Moscovici (2015), no intuito de tornar certas noções mais familiares e aplicáveis, a mencionada professora associa e desconsidera certas partes das noções teóricas, que talvez não se sejam tão familiares (ou dominadas), com conhecimentos que já possui (dominados). Por isso, os conceitos de gramática e competência comunicativa mesclam conhecimentos de tendências linguísticas distintas, hibridizando-os de forma harmônica para a compreensão da docente.

Examinemos outro comentário postado no ambiente virtual de aprendizagem do mesmo módulo do curso de extensão: 
Samara

A língua é um mecanismo vivo de comunicação. Através dela observamos a evolução de uma nação, pois ela é o reflexo da cultura e influências que um povo recebe do passado ao presente.

$\mathrm{O}$ estudo da gramática consiste no estudo dos elementos estruturais da língua, estabelecendo comunicação entre os falantes de forma clara e precisa, através de elementos coesivos, simples e práticos.

O professor deve ser dinâmico, ministrando o conteúdo de gramática de forma reflexiva em atividades contextualizadas, interdisciplinares, individuais ou coletivas de forma que o aluno passa a conhecer as variedades da língua através de pesquisas, as quais envolvam a leitura e produção textual, construindo seu próprio conhecimento linguístico. Bagno (2000 p. 87) opina que: "A gramática deve conter uma boa quantidade de atividades de pesquisa, que possibilitem ao aluno a produção de seu próprio conhecimento linguístico, como uma arma eficaz contra a reprodução irrefletida e acrítica da doutrina gramatical normativa".

A Língua Portuguesa requer muitas atividades, nas quais os gêneros textuais estejam inseridos, ou seja, o uso de propagandas, revistas, jornais, folhetins, bilhetes, receitas, enfim. E o fundamental e essencial a ser repassado aos estudantes não é tarefa difícil, um professor que esteja em constante evolução saberá como trabalhar assuntos interessantes de acordo a idade e série a ser ensinada.

Samara inicia seu comentário afirmando que a língua é uma forma de comunicação, intimamente relacionada a fatores sociais, históricos e culturais, do passado e do presente. Trata-se, a nosso ver, de uma forma particular encontrada pela mencionada professora para explicar satisfatoriamente o que seja língua, a partir da concepção de linguagem enquanto processo de interação.

$\mathrm{Na}$ sequência, ela considera que o ensino gramatical consiste no estudo dos elementos estruturais da língua. Essa forma de definir o estudo gramatical, principalmente por conta da noção de que a língua seja composta por elementos que lhe estruturam, remete à segunda concepção, instrumento de comunicação. O conhecimento de tais elementos contribuiria para que os falantes de uma língua organizassem sua comunicação de forma clara e precisa, justamente por empregarem elementos coesivos, simples e práticos. Do jeito como Samara explica parece-nos que o conhecimento gramatical seria responsável por lapidar a construção de enunciados, retirando-lhes quaisquer possibilidades de ambiguidade ou incompreensão por parte do coenunciador. Esses conhecimentos contribuiriam para a urdidura de enunciados com coesão, de forma simples e prática. Há explicitamente duas concepções de linguagem envolvidas nessa explicação sobre o ensino gramatical: expressão do pensamento e instrumento de comunicação. A primeira por conta da consideração de que a comunicação 
possa ser clara e precisa; a segunda devido ao fato de que, de algum modo, gramática está relacionada à estrutura linguística.

Baseando em Bagno (2000), Samara continua pontuando que o trabalho do professor deve ser dinâmico, o que implica no desenvolvimento dos conteúdos gramaticais de forma reflexiva por meio de atividades contextualizadas, interdisciplinares, individuais ou coletivas de modo que o estudante possa conhecer as variantes linguísticas através da realização de pesquisas. Essas pesquisas envolveriam leitura e produção, e contribuiriam, assim, para o desenvolvimento do conhecimento sobre a língua por parte do discente. Nesse ponto, a docente aborda a questão da abordagem de ensino e aprendizagem, demarcando que o ensino deveria ocorrer em uma visada mais construtivista (reflexão, contextualização, interdisciplinaridade, individual e coletivo) e não em uma visada tradicional. Essa abordagem daria conta, por conta do desenvolvimento de práticas de pesquisas, de desenvolver o conhecimento linguístico do estudante seja das diferentes variedades da língua portuguesa brasileira, seja de suas competências de leitura e de escrita.

Por fim, Samara termina seu comentário destacando que o ensino da língua portuguesa deve se pautar em textos de diferentes gêneros discursivos/textuais, a partir dos quais as atividades de ensino devem ser elaboradas. Conclui, então, que para um professor em constante desenvolvimento de seus saberes (TARDIF, 2013), a abordagem do objeto de ensino, isto é, a língua e, em específico, a gramática ocorrerá de forma mais fácil, conseguindo inclusive tornar os assuntos trabalhados interessantes à idade e ao ano escolar dos discentes. Notamos, então, que o ensino de língua portuguesa se pautaria, segundo Samara, em textos, aproximando-o, de um lado, da concepção de linguagem enquanto processo de interação e, de outro, da vertente de aprendizagem construtivista.

Percebemos no comentário de Samara que o ensino gramatical, de forma mais específica, abrange a concepção de linguagem enquanto expressão do pensamento e instrumento de comunicação; e, de modo mais amplo, possivelmente para aproximá-lo de uma abordagem de ensino mais construtivista, da concepção linguística como processo de interação. Assim, novamente, o que temos é uma hibridização de perspectivas e conhecimentos próprios de cada tendência linguísticas, colaborando, em certo sentido, para o desenvolvimento de uma prática de ensino e, consequentemente, de aprendizagem da língua, de forma mais interessante e apropriada aos estudantes. Porém, a professora demarca que isso requer dos docentes formação, possivelmente devido ao fato de que ainda se tenha, no 


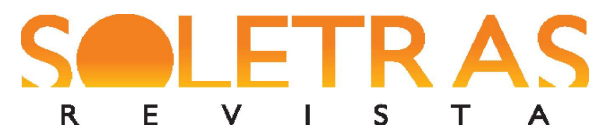

DOSSIÊ-N. 35 - 2018.1 - HERMES TALLES DOS SANTOS

contexto escolar - mas não exclusivamente - ainda o predomínio da corrente de ensino e aprendizagem tradicionalista e da linguagem enquanto expressão do pensamento.

\section{Considerações finais}

No Brasil, atualmente, o ensino de língua portuguesa orientado por documentos oficiais e noções científicas contemporâneas pauta-se na concepção de língua enquanto processo de interação. Essa concepção orienta a tomada do texto como base para a discussão dos processos de interação verbal, considerando fatores linguísticos, socioculturais, históricos e ideológicos, que são responsáveis, de algum modo, pela urdidura textual. Destarte, pelo menos, em tais documentos e orientações contemporâneas há um deslocamento da frase para o texto.

Entretanto, a prática cotidiana de ensino na Educação Básica ainda desenvolve propostas de estudo mais pautadas em frases, principalmente aquelas que concernem ao ensino gramatical, principalmente por conta de uma concepção de gramática e, nesse caso, indiretamente, também de língua, a partir da concepção de linguagem como expressão do pensamento. É preciso demarcarmos que é compreensível a influência que esta concepção linguística possui no contexto de ensino, visto que ela possui mais de dois milênios, tornando familiar a nomenclatura de classes de palavras e a análise gramatical, bem como a noção modelar de língua a gerações de pessoas, entre elas, os próprios professores que estão atuando na Educação Básica atualmente.

Analisando os comentários das duas professoras, notamos que conhecimentos, de certa maneira, oriundos de distintas concepções de linguagem. Isso possibilita-nos concluir que, na tentativa de desenvolver trabalhos satisfatórios de ensino, os professores hibridizam conhecimentos das três concepções de linguagem de forma coerente segundo a visão deles. Essas hibridizações são explicáveis por meio do fenômeno das representações sociais (MOSCOVICI, 2015), pois os docentes transformam conhecimentos relativamente desconhecidos/novos, recortando ou desconsiderando algumas questões e acomodando-os em meio a conhecimentos que já possuem. Isso resulta-lhes em conhecimentos coerentes e harmônicos, que sustentam e influenciam de suas práticas de ensino da língua portuguesa, além de construir-lhes noções particulares de língua.

A hibridização de conhecimentos proporciona que o professor - sem considerar que haja contradição entre as noções oriundas das diferentes concepções de língua e gramática, ou 


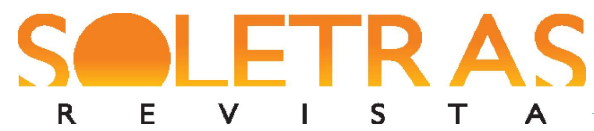

DOSSIÊ-N. 35 - 2018.1 - HERMES TALLES DOS SANTOS

fazendo com que tais contradições sejam em certo sentido apagadas- aborde aspectos relacionados aos textos, como exploração de efeitos de sentido, estrutura, função social, coesão, coerência, progressão temática... e questões mais gramaticais, como norma-padrão, classificação de classes de palavras, análise da estrutura e organização de sentenças, nomenclatura gramatical tradicional... Apesar de os alicerces de cada concepção de linguagem teoricamente compreenderem o que seja língua e gramática, de um ponto de vista certamente diferente e com implicações, em certo sentido, divergentes, na prática, mesmo conhecendo as implicações de cada uma das concepções, os docentes conseguem articulá-las, de modo que possíveis incongruências ou distensões sejam minimizadas e se tornem harmônicas. Destarte, podemos considerar que no contexto escolar brasileiro as viradas pragmática, textual e discursiva (BONINI, 2002; ROJO, 2008a, 2008b, 2010) realmente ocorreram, mas não deslocaram por completo o ensino gramatical. Conquanto o texto seja tomado como base para alguns objetivos de ensino da língua portuguesa, a frase ainda é o domínio central do ensino de gramática.

Por isso, a nosso ver, se quisermos uma mudança radical conforme preveem os documentos e orientações oficiais, de modo que o ensino linguístico seja pautado exclusivamente em textos, consideramos que seria interessante investirmos em formações docentes continuadas. Concomitantemente, julgamos também ser necessário conhecermos melhor e com mais delimitação as práticas e propostas desenvolvidas no contexto da Educação Básica e, a partir delas, desenvolvermos programas que possam ajudar os professores a compreender como conhecimentos científicos contemporâneos podem ajudá-los no desenvolvimento de ações pedagógicas mais satisfatórias e contribuir com a aprendizagem dos estudantes da língua portuguesa. Paralelamente, também a academia precisaria considerar que as práticas desenvolvidas pelos professores e seus conhecimentos podem auxiliar no desenvolvimento de conhecimentos científicos válidos e capazes de contribuir com o processo de ensino e aprendizagem. Seria, portanto, uma ação colaborativa, que aproximaria os contextos escolar e acadêmico, de forma mais profícua. Tal aproximação, no nosso entender, possibilitaria a construção de teorias próprias e adequadas a nossa realidade educacional, sem prejulgamentos ou imposições entre as partes envolvidas.

Por fim, gostaríamos de demarcar que nossa experiência de desenvolver formações continuadas em espaços virtuais, por meio de plataformas de educação a distância, tem se mostrado bastante satisfatória, mesmo com certa evasão dos participantes durante o 


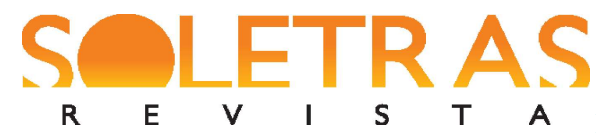

DOSSIÊ-N. 35 - 2018.1 - HERMES TALLES DOS SANTOS

desenvolvimento do curso, pois os professores podem participar e realizar as atividades previstas nos ambientes virtuais de aprendizagem em momentos dentro de suas possibilidades. As interações entre os participantes e a construção de saberes e conhecimentos se relevaram satisfatórias e correntes com os objetivos dos cursos ofertados. Além disso, os próprios professores solicitam que haja continuidade ou oferta de novos cursos com temáticas relacionadas ao campo educacional. Consideramos, portanto, que esse possa ser um espaço a ser explorado, cada vez mais, na formação continuada de docentes.

\section{Referências bibliográficas}

APARÍCIO, A. S. M. A proposta paulista de renovação do ensino de gramática dos anos 80/90. Trabalhos em Linguística Aplicada, Campinas, n. 37, p. 25-48, jan./jun. 2001.

BAGNO, M. Dramática da língua portuguesa: tradição gramatical, mídia \& exclusão social. São Paulo: Ed. Loyola, 2000.

BONINI, A. Metodologias do ensino de produção textual: a perspectiva da enunciação e o papel da Psicolinguística. Perspectiva, Florianópolis, v. 20, n.01. jan./jun., 2002.

BRASIL. Secretaria de Educação Fundamental. Parâmetros curriculares nacionais: terceiro e quarto ciclos do Ensino Fundamental: língua portuguesa. Brasília: MEC/SEF, 1998.

BRITTO, L. P. L. A sombra do caos: ensino de línguas x tradição gramatical. Campinas: Mercado de Letras, 1997.

FRANCHI, C. Mas o que é mesmo "gramática"? In: POSSENTI, S. (org.) Mas o que é mesmo gramática? São Paulo: Parábola, 2006ª p. 11-33.

. Criatividade e Gramática, in: POSSENTI, S. (org.) Mas o que é mesmo gramática? São Paulo: Parábola, 2006b, p. 34-101.

FREGONEZI, D. E. Aconteceu a virada no ensino de língua portuguesa? Revista do GELNE, Teresina, ano 1, n.2, p. 82-85, 1999.

GERALDI, J. W. Concepções de linguagem e ensino de português. In: O texto na sala de aula. Cascavel: Assoeste, 1984.

GNERRE, M. Linguagem, escrita e poder. São Paulo: WMF Martins Fontes, 2009.

HEINIG, O. L. de O. M. \& BUTTCHEVITZ, L. Os sentidos de gramática e linguagem para egressos do curso de letras. Anais do V Simpósio Internacional de Estudos de Gêneros Textuais, Caxias do Sul - RS, Agosto, 2009. 
KLEIMAN, A. B. \& CINTRA MARTINS, M. S. Formação de professores: a contribuição das instâncias administrativas na conservação e na transformação de práticas docentes, in: KLEIMAN, A. B. \& CAVALCANTI, M. (Orgs.) Linguística Aplicada: suas faces e interfaces. Campinas: Mercado das Letras, 2007, p. 273 -298.

LYONS, J. Introdução à Linguística Teórica. São Paulo: Nacional, 1979.

MOSCOVICI, S. Representações Sociais: investigações em Psicologia Social. Petrópolis: Vozes, 2015.

NEDER, M. L. C. Concepção de linguagem e ensino de língua portuguesa. Polifonia, Cuiabá, v. 1, n. 0, p. 71-89, 1993.

NEVES, M. H. M. A vertente grega da Gramática Tradicional: uma visão do pensamento grego sobre a linguagem. São Paulo: Editora da UNESP, 2005.

ROJO, R. H. Gêneros do Discurso/Texto como objeto de ensino de língua: um retorno ao trivium?, In: SIGNORINI, I. (Org.) [Re]discutir Texto, Gênero e Discurso. São Paulo: Parábola, 2008 a , p.73-107.

. O texto no ensino-aprendizagem de línguas hoje: desafios da contemporaneidade, in: TRAVAGLiA, L. C.; FINOTTI, L. H. B. et al. (Orgs.) Gêneros de texto:caracterização e ensino. Uberlândia: EDUFU, 2008b, p. 09-43.

. Introdução, in: SCHNEUWLY, B. \& DOLZ, J. Gêneros orais e escritos na escola. Campinas: Mercado de Letras, 2010.

SANTOS, Hermes Thalles. Representações sociais dos professores de língua portuguesa sobre o ensino gramatical. 2017, 339f. Tese (Doutorado em Estudos Linguísticos) - Centro de Educação e Ciências Humanas, Universidade Federal de São Carlos, São Carlos, 2017.

SOARES, M. Português na escola: história de uma disciplina curricular, in: BAGNO, M. Linguística da norma.São Paulo: Edições Loyola, 2012, p. 141-162.

SWALES, J. The concept of genre, in: . Genre analysis: English in academic and research settings. Glasgow: Cambridge University Press, 1990, p. 33-67.

TARDIF, M. Saberes docentes e formação profissional. Petrópolis: Vozes, 2013.

TRAVAGLIA, L. C. Gramática e interação: uma proposta para o ensino de gramática. São Paulo: Cortez, 2009.

VOLOCHÍNOV, V. N./BAKHTIN, M. Marxismo e Filosofia da Linguagem. São Paulo: HUCITEC, 2006.

WEEDWOOD, B. História concisa da linguística. São Paulo: Parábola Editorial, 2002. 


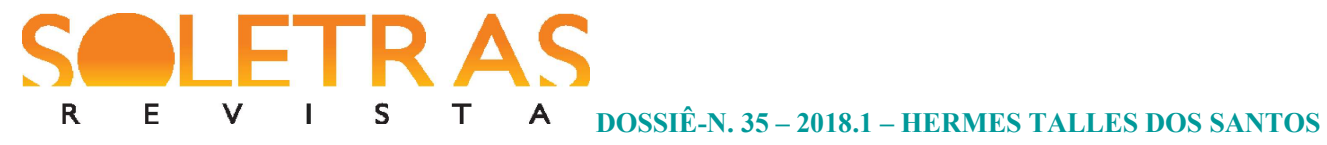

\section{Portuguese language teaching: between the sentence and the text at the classroom}

Abstract: In Brazil, Portuguese Language Teaching, in special Grammar, has been the center of attention of different specialists and theoretical language scholars whose aim is to provide learning process which is more suitable and consistent with contemporary scientific linguistic guidelines and theories. Therefore, considering and explaining the choice of using text as the basis of contemporary mother tongue teaching, we briefly return to some questions related to the conceptions of language to explain how each one influences language and grammar teaching. Then, aiming to understand the knowledge and considerations evidenced by teachers, we analyzed two comments posted in a virtual learning environment of a distance learning course designed for Portuguese language teachers. Thus, we verified that the mentioned course improved teachers' knowledge and demonstrated that there is a need for further rapprochement between the academic and scholar context, so that the building of knowledge about Portuguese language and grammar teaching can be consistent with the Brazilian educational environment.

Keywords: Portuguese language. Grammar. Teaching and learning. Continuing teacher formation.

Recebido em 21 de dezembro de 2017.

Aprovado em 05 de fevereiro de 2018. 